\title{
Multilingualism in Hong Kong City Edge: A Mixed Method Study on Linguistic Landscape in Stanley
}

\author{
Wenrui Zhang*, Jingwen Ou \\ Department of English, The Chinese University of Hong Kong, Hong Kong, China \\ *Corresponding author
}

\begin{abstract}
In the last few decades, there has been a surge of interest in the interdisciplinary study of linguistic landscape (LL), since LL has been viewed as the junction of sociolinguistics, applied linguistics, social psychology, geography, and media studies. However, little is known about the role of nonlinguistic features and the dynamism within a LL. Thus, this study aimed to investigate the multilingualism phenomena in Hong Kong revealed by LLs in Stanley using a mixed method approach. The result revealed that (1) all the official LLs were fixedly represented in Chinese and English (two official languages of Hong Kong); (2) foreign languages were found in non-official LLs for emblematic and tourism functions. Moreover, two types of relationship were found between the linguistic part and the non-linguistic part, (1) complementary and commercial relationship as well as (2) mutual translational relationship. The implications were three-fold. Theoretically, this study generated fresh insights into the interaction between linguistic and non-linguistic parts on LLs. Methodologically, mixing quantitative analysis and critical discourse analysis achieved a methodological triangulation, and further led to a comprehensive understanding. Practically, LL proves its value in English instruction due to its authenticity, dynamism, and easy accessibility.
\end{abstract}

Keywords: Linguistic Landscape; Multilingualism; Hong Kong

\section{Introduction}

The interdisciplinary study of linguistic landscape (LL) has received considerable scholarly attention in recent years, since LL has been viewed as the junction of sociolinguistics, applied linguistics, social psychology, geography, and media studies (Sebba, 2010). The term "linguistic landscape" was initially defined as the visualized languages, i.e., the languages of public and commercial signs in a certain territory (Landry \& Bourhis, 1997). Recent trends in LL have led to a proliferation of studies that have been carried out in major regions in the world, including Athens (Nikolaou, 2017), Tokyo (Backhaus, 2006), and Hong Kong (Jaworski \& Yeung, 2010; Lai, 2013). Previous studies on the LL of Hong Kong mainly concentrate on the semiotic meanings of addresses and the power relationship among different ethnic groups. However, the role of non-linguistic features and the dynamism within a LL have hitherto received scant scholarly attention (Macalister, 2012). This study is therefore designed to generate fresh insight into the multilingualism in Hong Kong revealed by LLs in an exotic coastal town--Stanley adopting a mixed method approach.

\section{Literature Review}

\subsection{Relevant Definitions of The Linguistic Landscape}

In order to guarantee the validity of data, the categorization and criteria of definitions should be clarified. The concept of LL has been discussed and widely interpreted in several different ways in a long time. It can be illuminated as the language distribution in a certain region (e.g. the Baltic area by Kreslins, 2003) or the representation of the social context and multilingualism (Macalister, 2012). Compared with the above-mentioned notions, the definition of LL proposed by Landry and Bourhis (1997) is chosen as the core concept of this study since it is not only widely acknowledged by specialists (e.g., Gorter 2006), but also sets up a standard for this study particularly in the categorization process. In addition to the basic concept of LL, more divisions are required between official signs and nonofficial signs (Backhaus, 2006). Official signs represent the signs made by governmental or non-governmental organizations such as Leisure and Cultural Services Department in Hong Kong, while nonofficial signs 
normally mean the signs set up by individuals or companies for the purposes of profits. What's more, the dominant language of a certain area will appear on official signs with fixed formats, while the nonofficial signs usually cover multiple languages. The content and format will be changed according to the diversity of the purposes. What should also be noticed is that LL consists of linguistic and non-linguistic parts such as location, letter font, sign size and pattern, which are also worth discussing due to its potential business value (Ben-Rafael, 2008).

\subsection{Sociolinguistic Backgrounds of Hong Kong}

Hong Kong, a Special Administrative Region under the sovereignty of The People's Republic of China (PRC) since 1997, enjoys rich ethnic and linguistic variety. The 'One country, Two systems' political principle endows Hong Kong a high degree of autonomy in managing affairs such as establishing its own language policy, i.e., trilingual (i.e., able to speak Cantonese, English, and Putonghua) and biliterate (i.e., be proficient in writing both English and Chinese) (Evans, 2013; Poon, 2010). Accordingly, English serves as the major language of the government, law courts, international businesses and education whilst Chinese is viewed as the means of daily communication among the general public (Lai, 2013). Language policy plays a vital role in modeling LLs, which is a vivid reflection of local residents' language identities (Dal Negro, 2008). Thus, traditional Chinese script and English are frequently seen in the LLs of Hong Kong, which bestows Hong Kong people a distinctive identity that distinguishes them from people in the mainland, where most of the LLs are written in simplified characters (Lai, 2013). In the Hong Kong context, English marks its modernity whereas Chinese denotes the localization and solidarity (Liu, 2018).

Stanley is an exotic scenic spot located in the southeast part of Hong Kong island because of its British occupation and Japanese invasion history. Nowadays, a sizable foreign population including ethnic minority groups lives there. The LLs in Stanley are therefore expected to demonstrate abundant evidence of multilingualism with local idiosyncrasies that are different from those in normally researched city centers (e.g., Central). What remains ambiguous is the role of minority languages that are always found in nonofficial LLs (Holmes \& Wilson, 2017). Built upon this, the current study analyzed both official LLs and nonofficial LLs.

\subsection{Previous Studies on Linguistic Landscape}

Recent years have witnessed a growing academic interest in LL studies. Numerous studies have been undertaken in officially bilingual cities such as Canada, populous cities like Bangkok, and international cities like Paris (Backhaus, 2007; Gorter, 2006). These studies concentrate on a similar topic, i.e., the division of appearance on official and nonofficial LLs, including the research into the relationship between power and solidarity from the perspectives of local idiosyncrasies revealed by languages, language mixing and language identity. Specifically, in Hong Kong, researchers have devoted extensive effort to investigate not only the semiotic meanings, roles, and status, but also the power relationship among the languages on signs, where Lai (2013)'s study particularly establishes a comprehensive baseline through analyzing 1160 assembled photographic evidence for future studies' reference. According to Lai (2013), Hong Kong displays a largely bilingual profile of English and Chinese, where English represents internationalization and local identity while Chinese is the marker of national identity. However, few studies have explored how non-linguistic features affect the linguistic power relationship and the stability and dynamism within a LL (Macalister, 2012).

Drawing upon the existing research gaps, this paper attempts to address the following questions: (1) What are the distributions of languages used on the signs in Stanley? (2) To what extent do linguistic landscapes display the dynamic and static aspects of language identity within the Hong Kong city edge? (3) What is the mutual relationship among each part of the signs (i.e., linguistic part and non-linguistic part)?

\section{Methodology}

\subsection{Data}

For the present study, data of signs were collected in the form of photos from three arteries around the commercial center of Stanley as commercial centers are believed to contain intense distributions of various signs. The photos are later sorted and uploaded onto OneDrive.com for storage's purpose. The 
scope of signs being included as the source of data highly is consistent with the well-established and well-accepted definition of LL, i.e., public road signs, commercial billboards, street and place names, commercial shop signs and public governmental signs (Landry \& Bourhis, 1997, p.205). Yet there is still a need to mark out the boundaries between the LL on the signs and those on the extended dimensions such as restaurant menus, 'vehicles, T-shirts, magazines' (Curtin, 2009), 'graffiti' (Pennycook, 2008), or even the signs above the ground-floor level as multi-storey buildings are such typical scenes across Hong Kong. The extended dimensions were also included in the photos collected to ensure the diversity and richness of data sources.

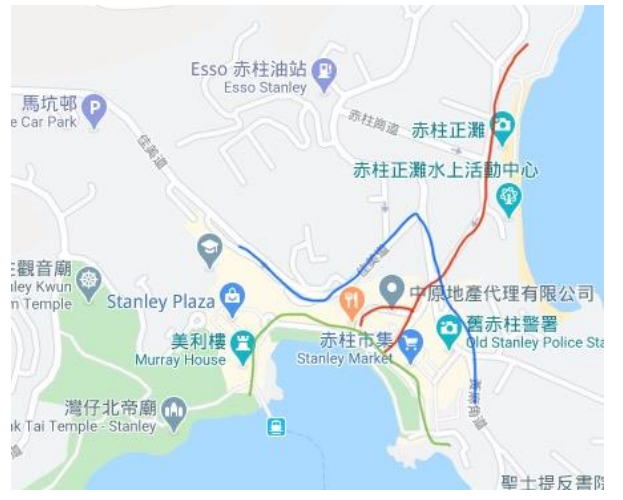

Figure 1: Map of Stanley

It is also necessary to clarify the meaningful unit for the quantitative analysis in the later section as both singular and multiple signs could be contained in one photo. In the current study, one coherent appearance of signs (i.e. either only one sign on one billboard or multiple signs on many as long as they share the same purposes) is taken as the criterion for a single unit.

For example, although there are four boards in the image below, they are counted as three signs due to different purposes served.

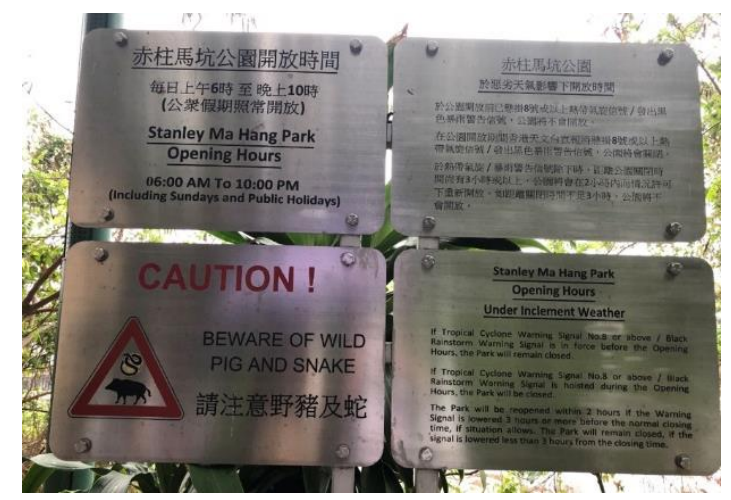

Figure 2: Example 1

Another example, in the following photo the signs are counted as two. The signs on top are used to indicate directions while the one below is a notice board.

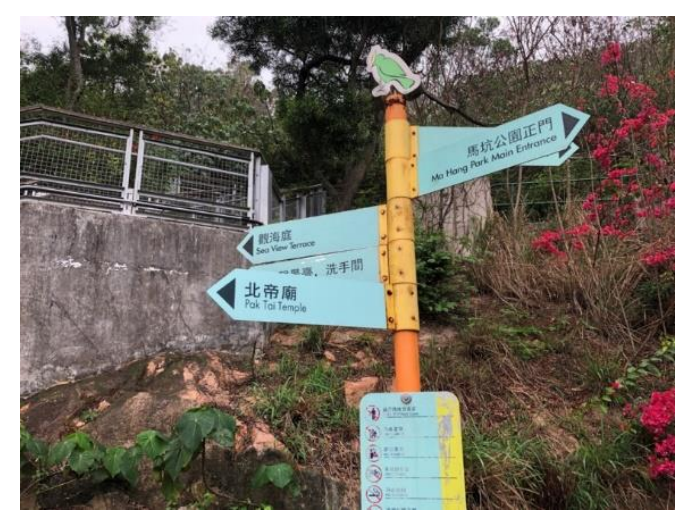

Figure 3: Example 2 


\subsection{Methods of Analysis}

A mixed method design is applied in this study, including the process of the photo collection for quantitative data analysis and the qualitative critical discourse analysis. General analysis procedures follow the framework set up by renowned scholars, which incorporates data cleaning, categorization processes and a 'sign coding scheme' (Ben-Rafael, Shohamy, Hasan Amara, \& Trumper-Hecht, 2006; Calvet, 1994; Lai, 2013). The data cleaning process intends to validify the representativeness and credibility of the data. It also purposefully eliminates the kinds of signs that (1) are repeated and blurred, and (2) have no linguistic contents or have only one type of language (since monolingualism is not the focus) (Lai, 2013, p.256). Given the amount of the signs collected, there exists an urgent need to adopt a proper categorization standard. The process of cataloguing in the study follows the tradition established by Ben-Rafael et al. (2006) and Calvet (1994), where signs are classified into official (also "in vitro") and nonofficial (also "in vivo"). More details are shown in the Table 1 below.

\section{Table 1: Categorization standard}

\begin{tabular}{|l|l|}
\hline Category & Details \\
\hline official \& "in vitro" & $\begin{array}{l}\text { Public signs on government building, signs of street names, signs of } \\
\text { place names, road signs, public signs of general interest, public } \\
\text { institution signs }\end{array}$ \\
\hline nonofficial \& "in vivo" & $\begin{array}{l}\text { Store signs, commercial billboards, signs or announcements from } \\
\text { private business }\end{array}$ \\
\hline
\end{tabular}

The aforementioned coding scheme proposes to discover the hidden non-linguistic features and the secrets of the mutual relationship among languages on the LLs. Analysis might be conducted from various perspectives such as sign location, font sizes, number of languages, the order of each language and the translational relationship amongst (Gorter, 2006, p.3).

\section{Findings}

The results of data collection are summarized in three tables separately. As Table 2 suggested, the distribution of different languages in Stanley's center area illustrates an obvious distinction. English (98.9\%) and Chinese (93.1\%) account for a large percentage of the total number of the signs, whilst the minority languages i.e., Korean (1.1\%) and French (1.1\%), are seldomly seen on the signs.

Table 2: Number of appeared languages

\begin{tabular}{|c|c|c|}
\hline Language & Number & Percentage \\
\hline English & 86 & $98.9 \%$ \\
\hline Chinese & 81 & $93.1 \%$ \\
\hline Korean & 1 & $1.1 \%$ \\
\hline French & 1 & $1.1 \%$ \\
\hline In total & 87 & $100 \%$ \\
\hline
\end{tabular}

The statistics in Table 3 reveals that the LLs in Stanley are composed of both monolingual and bilingual signs. However, the expected high frequency of multilingualism emergence in the literature review is not exhibited in this research. It is clear that the bilingual signs of Chinese and English frequently appear in this area, which takes almost $91 \%$ of the total number. Apart from the existence of a high percentage of bilingualism, the monolingual signs should also be noticed. There are 7 monolingual signs in full, all of which take the form of advertisement for the profit purpose.

Table 3: Number of monolingual and bilingual signs

\begin{tabular}{|l|l|l|}
\hline & Number & Percentage \\
\hline Bilingual & 80 & $92 \%$ \\
\hline Chinese \& English & 79 & $90.9 \%$ \\
\hline English \& Korean & 1 & $1.1 \%$ \\
\hline Monolingual & 7 & $8 \%$ \\
\hline Chinese only & 1 & $1.1 \%$ \\
\hline English only & 5 & $5.7 \%$ \\
\hline French only & 1 & $1.1 \%$ \\
\hline In total & 87 & $100 \%$ \\
\hline
\end{tabular}


Based on the data collection provided in Table 4, the number of official signs (77) is much higher than that of nonofficial signs (10). One potential explanation for this phenomenon might be that the LL planning in scenic spots is determined more by the authorities than by the citizens.

Table 4: Number of official and nonofficial signs

\begin{tabular}{lll}
\hline & Number & Percentage \\
\hline Official signs & 77 & $88.5 \%$ \\
Nonofficial signs & 10 & $11.5 \%$ \\
In total & 87 & $100 \%$ \\
\hline
\end{tabular}

\section{Discussion}

\subsection{Distributions of Languages}

There are 4 languages found on the assembled LLs of Stanley: English, Chinese, Korean, and French, with Chinese and English taking the predominant position among them. All the official signs collected in Stanley are written in Chinese and English due to the prevalent bilingual culture and language policy in Hong Kong (Lai, 2013).

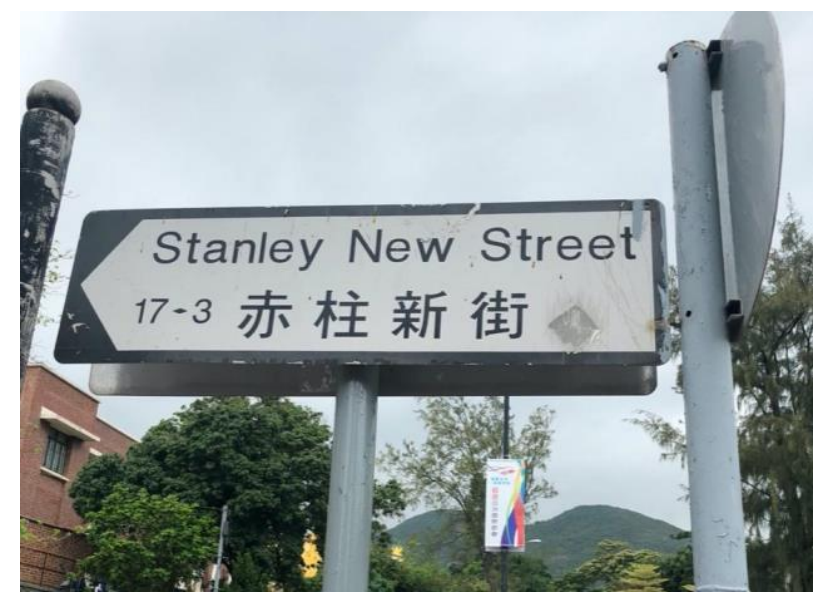

Figure 4: Official road sign

Nonofficial signs gathered are more diversified in forms and less restricted by language policy than official ones. Nonofficial LLs usually demonstrate the linguistic flexibility, where both bilingual and monolingual evidence can be found ( $\mathrm{Lu}, \mathrm{Li}, \& \mathrm{Xu}, 2020)$. Signs written in English and Chinese remain salient because of (1) the symbolic meanings of English (i.e., the representation of 'two systems' \& the icon of westernization and attractiveness), (2) the accessibility of Chinese to the local community (Lai, 2007).

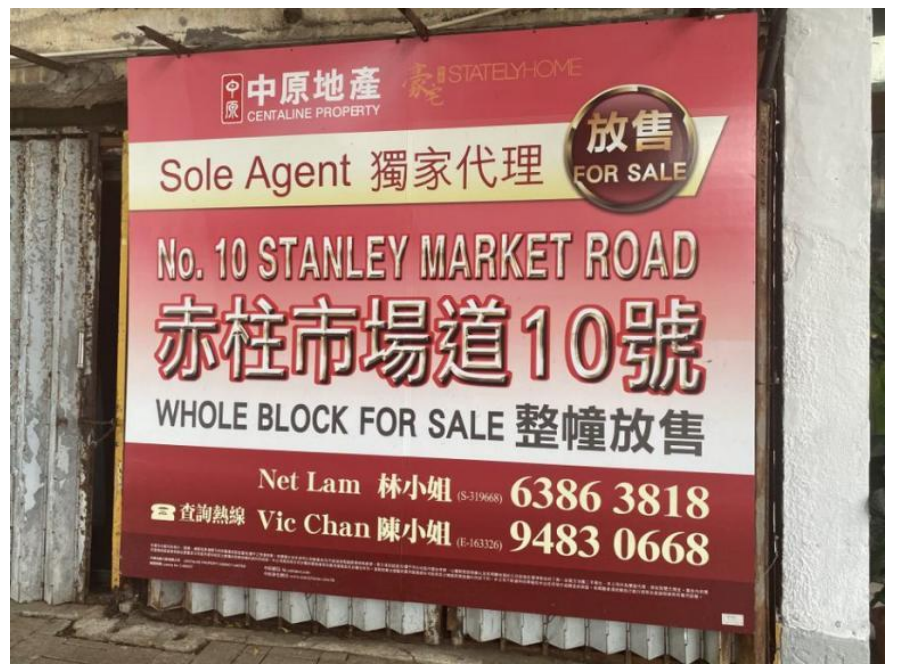

Figure 5: Advertisement 
Minority languages (i.e., French, Korean) also appear on LLs , although their respective population sizes are relatively small. Such visibility can be attributed to their prestige in terms of style, fame, and quality (Lai, 2013). Similarly, Brock (1991) states that foreign languages on commercial signs often perform their ornamental function rather than the communicative role. Furthermore, concerning Stanley's identity of the scenic spot, the minority languages on nonofficial signs aim to attract tourists from different regions.

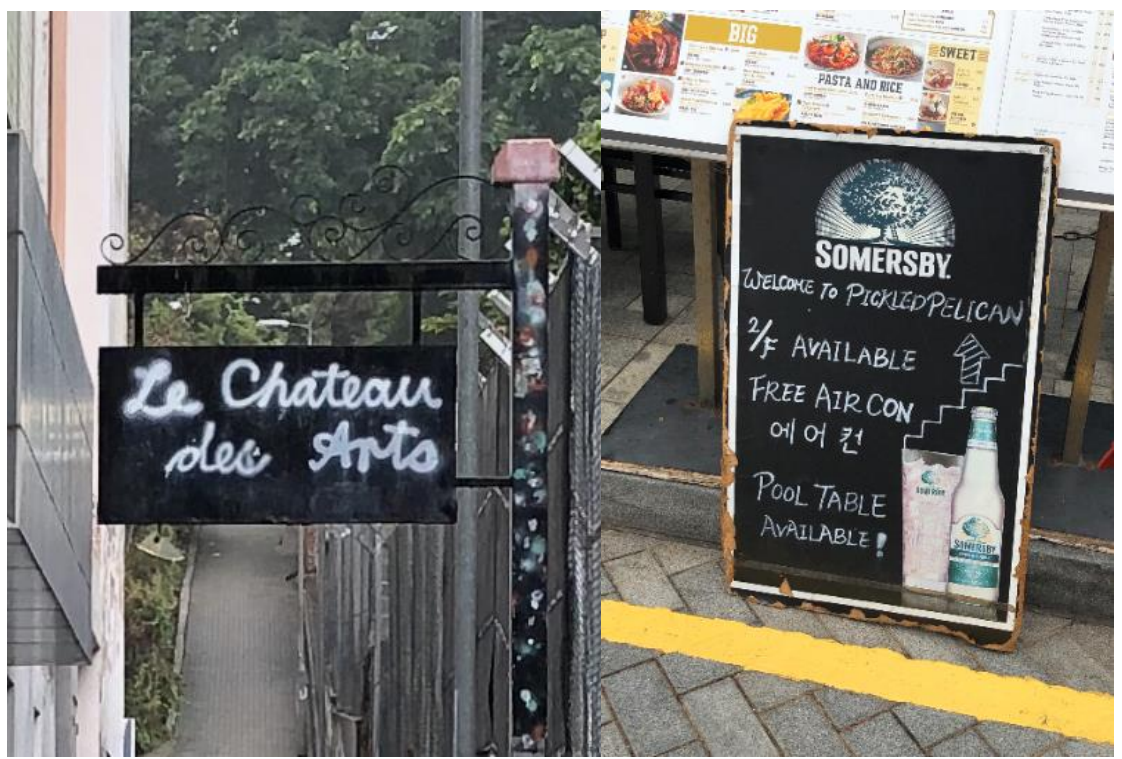

Figure 6: Minority languages on nonofficial signs

In short, the official languages on official LLs fulfil their informational functions whilst the language choices on unofficial LLs convey their symbolic meanings (Landry \& Bourhis, 1997).

\subsection{Stability and Dynamism in the LLs}

Apart from sorting LLs into official and nonofficial ones, they can also fall under the classifications of "in vitro" (i.e., static) and "in vivo" (i.e., dynamic) (Calvet, 1994). Macalister (2012) further illustrated that official signs and those with shared national or corporate conventions, usually with identical forms, would appear to be more static and permanent. They tend to have much more in common than the nonofficial ones, which are intended for the use of local companies and individuals to present creativity and idiosyncrasy regarding the contents of the signs. Compared with the static signs, which basically adopt the "top-down" pattern, those dynamic ones are more "bottom-up" in nature as they are generated from the "grassroots" with unique idiosyncratic linguistic and non-linguistic features (Macalister, 2012). Table 5 quoted from Macalister (2012) is to clarify the degree of permanence between stability and dynamism in the LLs of Stanley and try to demystify the language identity of local people regarding the linguistic and non-linguistic representations on the signs.

Table 5: Linguistic landscape by whom?

\begin{tabular}{|l|l|l|l|l|}
\hline In vitro & \multicolumn{2}{c|}{ In vivo } \\
\hline Official & $\begin{array}{l}\text { Commercial } \\
\text { national }\end{array}$ & Commercial local & Community local & Individual \\
\hline
\end{tabular}

After a closer look at the valid photo data, it is discovered that Stanley, a heated local tourist destination, displays distinctive dynamism in LLs, especially through entities of community local and commercial local, given the fact that signs by these two entities take up apparently higher proportions in general. Private signs are rarely depicted. The signs categorized under "official" were static in nature, given their relatively identical linguistic features conventionalized nationwide under the stipulations of governmental language policies, yet they still stood along with those established by local communities to endow a sense of uniqueness in terms of LLs in Stanley.

To fully explore the varying degree of dynamism, the public signs, local-community LLs and local commercial signage are analyzed as follows.

Public signs generally appear bilingually (sometimes multilingual and include sign language) with 
rich semiotics on the boards for people's reference. They are usually permanent and carefully designed by official institutes. Nevertheless, they are more dynamic than the kind of signs set up by local communities long ago since those are always historic, which means the signs might be refurnished but never be totally replaced due to governmental protection. They were kept in their original taste while the public signs established recently are new, creative and better catering to public needs. The dynamism seems to be displayed through linguistic and semiotic resources adopted.

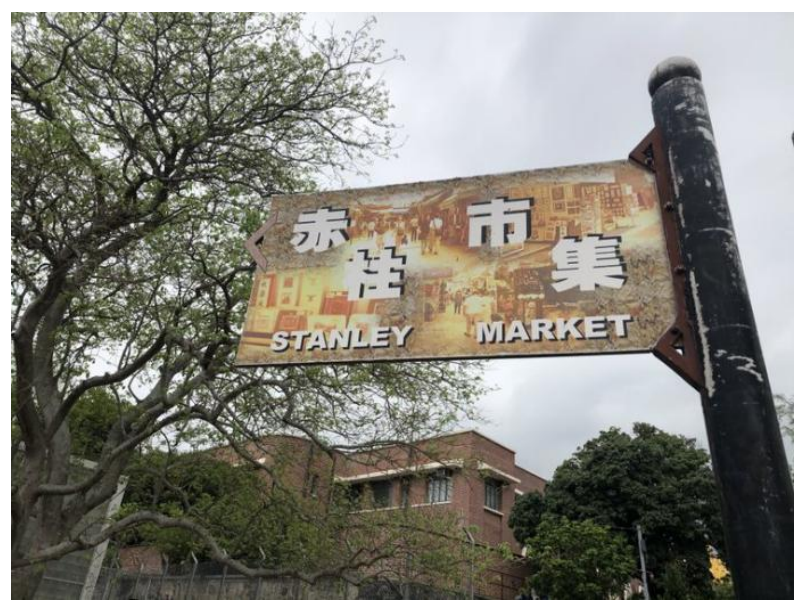

Figure 7: Public sign

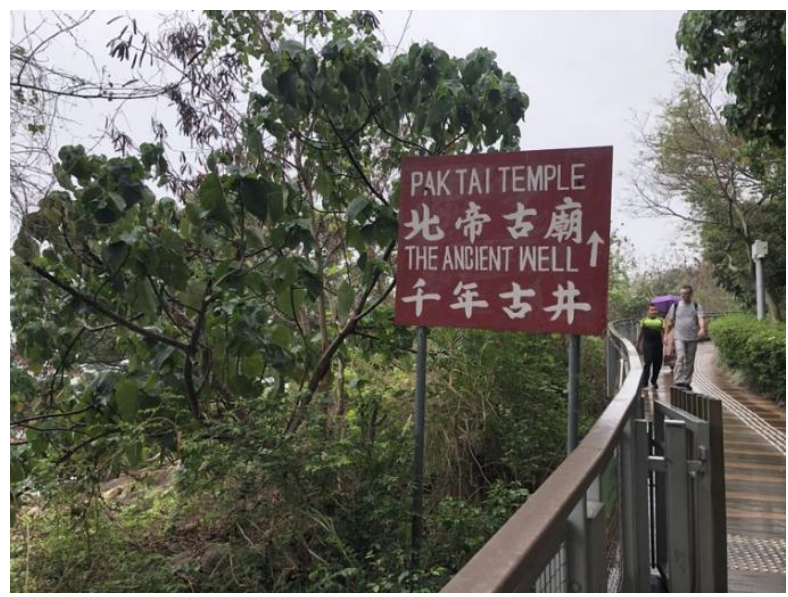

Figure 8: Old sign designed by local communities

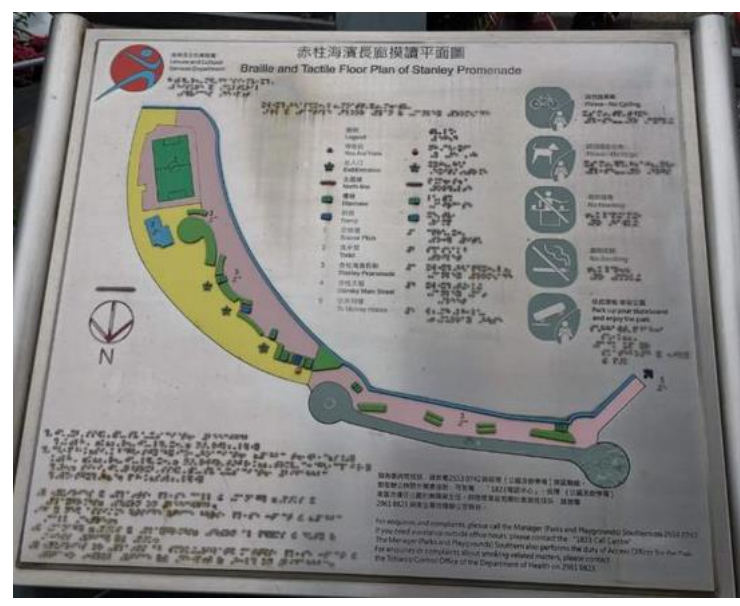

Figure 9: New public sign

Greater dynamism is found in the photos of local commercial signs where both linguistic (using two or more languages for translations or illustrations) and non-linguistic features (font, letter size, color, layout, pattern, semiotics, etc.) are incorporated into the whole design of the signs. The diversity shown from local commercial signs and linguistic choices presents the language identity preferred by the local 
business since Stanley is an international and tourism town with high degree of language tolerance, which is consistent with the macro-environment in Hong Kong despite its remote location. The constant economic boom brought by heated tourism implies a relatively high possibility of LL changes around the town center of Stanley.

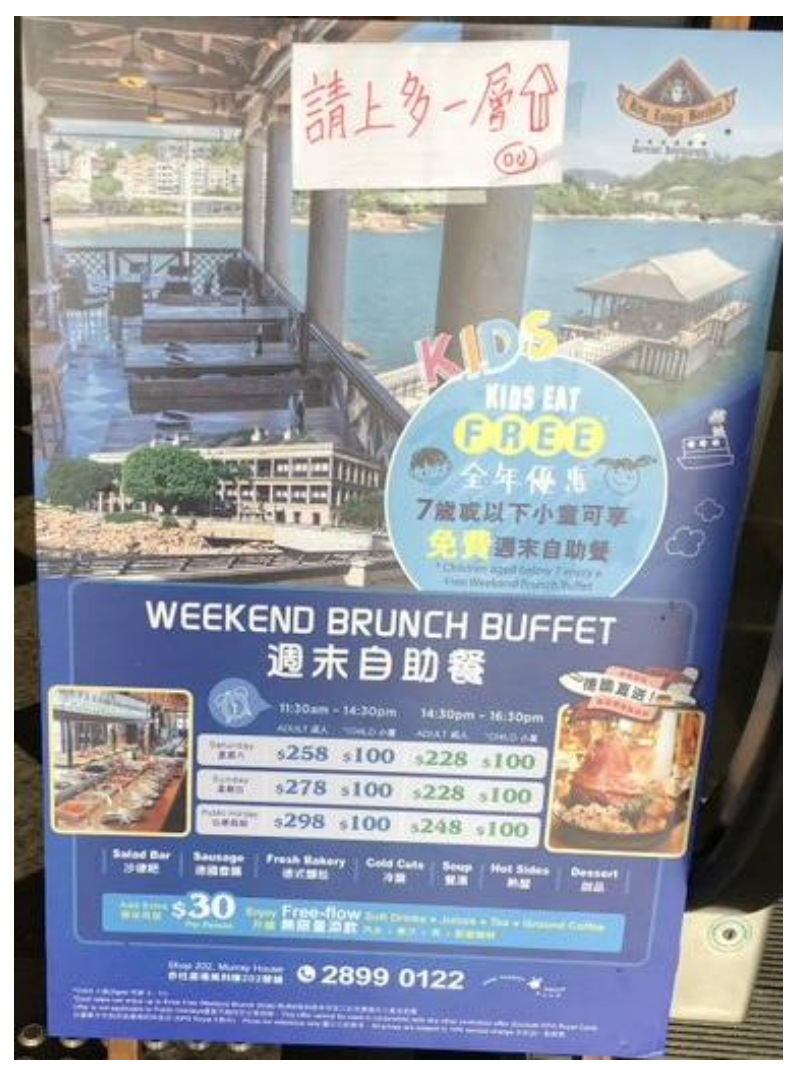

Figure 10: Local commercials sign

\subsection{Mutual Relationship}

According to Kravchenko (2003) the LLs are not limited to the linguistic part, it also contains the non-linguistic part, which is especially common in nonofficial signs. For the third question concerning the linguistic and nonlinguistic parts of signs, different kinds of mutual relationship can be analyzed based on different purposes.

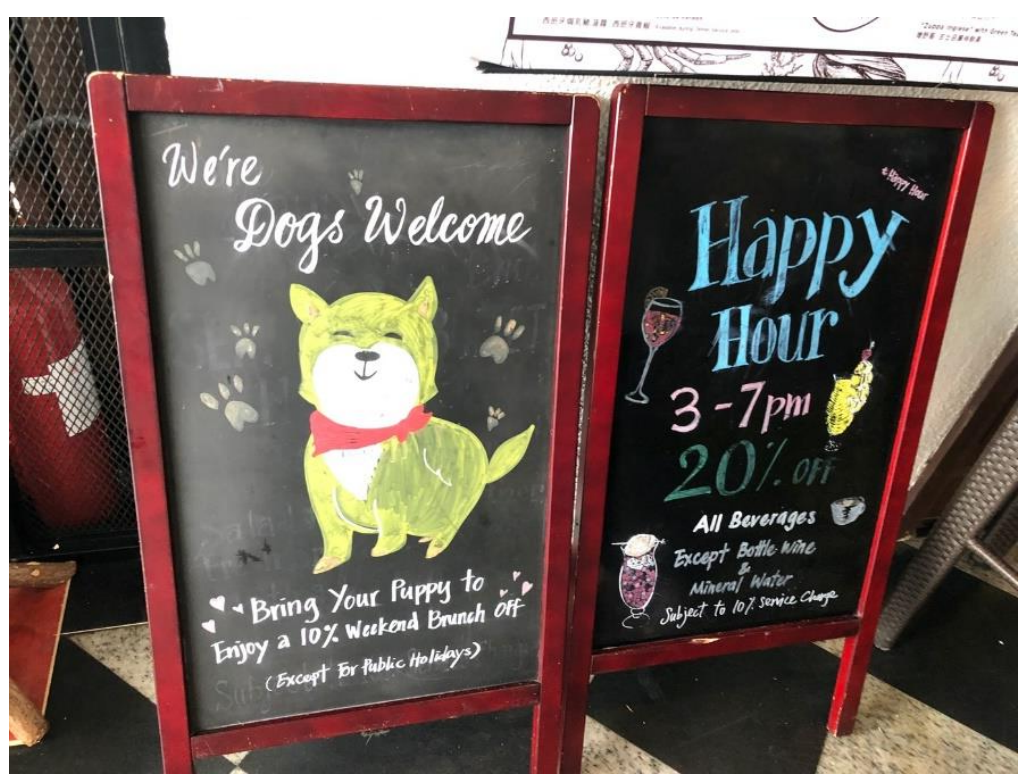

Figure 11: Complementary and propagandistic correlations between linguistic and non-linguistic parts 
Firstly, concerning the relationship between the linguistic and non-linguistic part, it is either complementary or propagandistic. For instance, as suggested from Figure 11, the dog and drink paintings all belong to the non-linguistic part of signs. On the one hand, combined with the information of 'We're dogs welcome', it can be revealed that the pattern of the dog is an explanation for the words above. These two parts can therefore be viewed as having a supplementary relationship. On the other hand, the adorable dog on the left is painted to create a harmonious atmosphere of the restaurant so as to attract the customers. By the same token, this non-linguistic part plays a significant role in the function of propaganda.

Secondly, there are two basic types of bilingual signs, i.e., those containing mutual translations and those do not (Backhaus, 2006). Out of 80 bilingual LLs gathered, no evidence is found indicating the latter type. All of the collected bilingual signs written in Chinese and English show the translation relationship. For example, in the official sign published by Leisure and Cultural Services Department, the English version is the translation of the Chinese version. i.e., “嚴禁吸烟' can be translated into 'No smoking'. Due to the lack of knowledge in Korean, the English-Korean bilingual sign in this study is not taken into consideration.

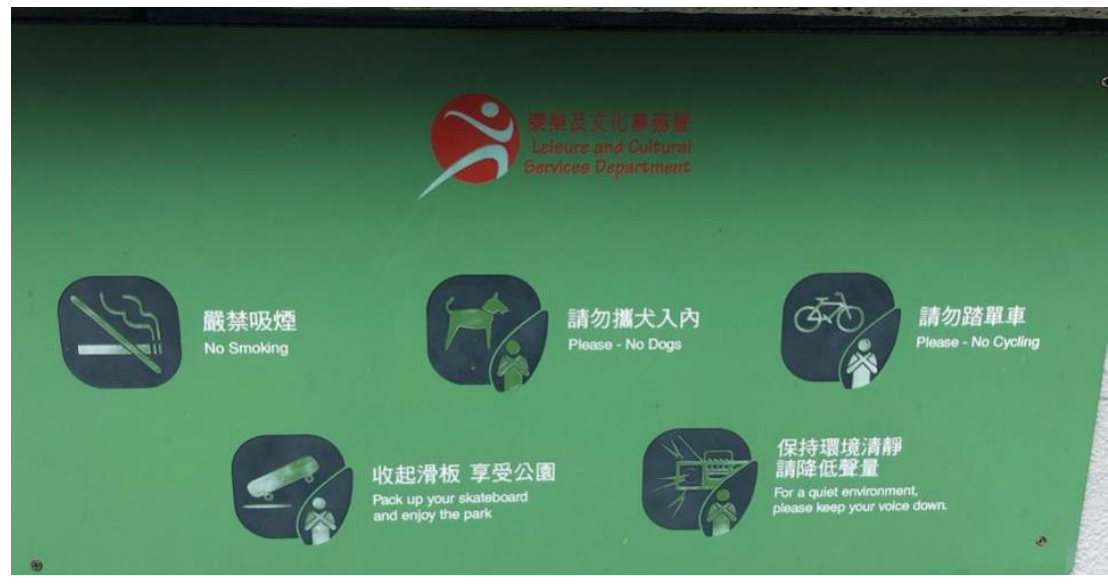

Figure 12: Translational relationship between English and Chinese

\section{Conclusion}

This study sets out to investigate the interpretation of multilingualism shown from LLs in Hong Kong city edge. As evidenced in the assembled signs, all of the official LLs are stably fixed in Chinese and English. These two languages are principal components of signs, which constitute the foreground of Hong Kong (Lai, 2013). Foreign languages (i.e., French, Korean) are found in dynamic nonofficial LLs to display their emblematic functions and attract tourists. Moreover, there are two types of relationship found within the compositional elements of the signs assembled: (1) complementary and commercial relationship among linguistic and non-linguistic parts and (2) mutual translational relationship regarding the linguistic parts.

This study has multifaceted implications. Theoretically, these findings contribute to deepening the understanding of LLs in Hong Kong city edge. Methodologically, the adoption of a mixed method approach by mixing quantitative analysis and critical discourse analysis allowed the application of methodological triangulation, which not only leads to a relatively holistic understanding, but also increases the validity of this study. Practically speaking, there are a few future orientations that this study could be extended to. Firstly, LL can be used in EFL instructions with various pedagogical goals given its authenticity, dynamism and easy accessibility (Rowland, 2013). Secondly, future studies on similar topics would be intriguing and worthy of high academic value by investigating interpretations of LL with more sufficient data. Given that the sample size, especially the data of nonofficial signs, in the present study is not large enough to yield a statistical representation as it is inconvenient to go into private shops or restaurants frequently where more evidence can be found.

\section{References}

[1] Backhaus, P. (2006). Multilingualism in Tokyo: A look into the linguistic landscape. International Journal of Multilingualism, 3(1), 52-66. 
[2] Backhaus, P. (2007). Linguistic landscapes: A comparative study of urban multilingualism in Tokyo (Vol. 136): Multilingual Matters.

[3] Ben-Rafael, E. (2008). A sociological approach to the study of linguistic landscapes. In Linguistic Landscape (pp. 48-62): Routledge.

[4] Ben-Rafael, E., Shohamy, E., Hasan Amara, M., \& Trumper-Hecht, N. (2006). Linguistic landscape as symbolic construction of the public space: The case of Israel. International Journal of Multilingualism, 3(1), 7-30.

[5] Brock, M. N. (1991). The good feeling of fine': English for ornamental purposes. English Today, 7(2), 50-51.

[6] Calvet, L.-J. (1994). Les voix de la ville: Introduction à la sociolinguistique urbaine: Payot.

[7] Curtin, M. (2009). Indexical signs, identities and the linguistic landscape of Taipei. Linguistic landscape: Expanding the scenery, 221-237.

[8] Dal Negro, S. (2008). Local policy modeling the linguistic landscape. In Linguistic Landscape (pp. 246-258): Routledge.

[9] Evans, S. (2013). The long march to biliteracy and trilingualism: Language policy in Hong Kong education since the handover. Annual Review of Applied Linguistics, 33, 302-324.

[10] Gorter, D. (2006). Linguistic landscape: A new approach to multilingualism: Multilingual Matters. [11] Holmes, J., \& Wilson, N. (2017). An introduction to sociolinguistics fifth edition: Routledge.

[12] Jaworski, A., \& Yeung, S. (2010). Life in the Garden of Eden: The naming and imagery of residential Hong Kong. Linguistic landscape in the city, 153-181.

[13] Kravchenko, A. V. (2003). The ontology of signs as linguistic and non-linguistic entities: a cognitive perspective. In Annual Review of Cognitive Linguistics (pp. 179-191): John Benjamins.

[14] Kreslins, J. (2003). Linguistic landscapes in the Baltic. Scandinavian Journal of History, 28(3-4), 165-174.

[15] Lai, M. L. (2007). Exploring Language Stereotypes in Post-colonial Hong Kong through the Matched-guise Test. Journal of Asian Pacific Communication, 17(2), 225-244.

[16] Lai, M. L. (2013). The linguistic landscape of Hong Kong after the change of sovereignty. International Journal of Multilingualism, 10(3), 251-272.

[17] Landry, R., \& Bourhis, R. Y. (1997). Linguistic landscape and ethnolinguistic vitality: An empirical study. Journal of language and social psychology, 16(1), 23-49.

[18] Liu, X. (2018). A comparative study of language attitudes in Hong Kong: Towards English, Cantonese and Putonghua. International Journal of English Linguistics, 8(3), 195-209.

[19] Lu, S., Li, G., \& Xu, M. (2020). The linguistic landscape in rural destinations: A case study of Hongcun Village in China. Tourism Management, 77, 104005.

[20] Macalister, J. (2012). Language policies, language planning and linguistic landscapes in TimorLeste. Language Problems and Language Planning, 36(1), 25-45.

[21] Nikolaou, A. (2017). Mapping the linguistic landscape of Athens: The case of shop signs. International Journal of Multilingualism, 14(2), 160-182.

[22] Pennycook, A. (2008). Linguistic landscapes and the transgressive semiotics of graffiti. In Linguistic Landscape (pp. 342-352): Routledge.

[23] Poon, A. Y. (2010). Language use, and language policy and planning in Hong Kong. Current issues in language planning, 11(1), 1-66.

[24] Rowland, L. (2013). The pedagogical benefits of a linguistic landscape project in Japan. International Journal of Bilingual Education and Bilingualism, 16(4), 494-505.

[25] Sebba, M. (2010). Linguistic Landscapes: A Comparative Study of Urban Multilingualism in TokyoPeter Backhaus. Writing Systems Research, 2(1), 73-76. 